\title{
Habitat selection and activity patterns in Alpine mountain hare (Lepus timidus varronis)
}

\author{
Francesco Bisi ${ }^{\mathrm{a}, *}$, Mosé Nodari $^{\mathrm{a}}$, Nuno Miguel Dos Santos Oliveira ${ }^{\mathrm{c}}$, Federico Ossi $^{\mathrm{a}}$, Elisa Masseroni $^{\mathrm{b}}$, \\ Damiano Giovanni Preatoni ${ }^{a}$, Lucas Armand Wauters ${ }^{a}$, Adriano Martinoli ${ }^{a}$
}

a Department of Theoretical and Applied Sciences, University of Insubria, Via J. H. Dunant 3, 21100 Varese, Italy

${ }^{\mathrm{b}}$ Institute Oikos, Via Crescenzago 1, 20134 Milano, Italy

c Animal Biology Department, Faculty of Science, University of Lisbon, Portugal

\section{A R T I C L E I N F O}

\section{Article history:}

Received 17 February 2012

Accepted 31 May 2012

\section{Keywords:}

Lepus timidus

Habitat selection

Landscape structure

Italian Alps

Activity patterns

\begin{abstract}
A B S T R A C T
We investigated activity patterns and habitat use of 34 radio-tracked mountain hares (Lepus timidus) in the Italian Alps. We first showed that hares were nocturnal and that activity patterns changed seasonally in parallel with circadian rhythms. We predicted that day home ranges will include suitable resting (shelter) habitats, and night home ranges will primarily include suitable foraging habitats. A hare's nightrange was larger than its day-range. On average, night and day ranges overlapped by $36 \%$, suggesting that selective pressures affecting space use were, at least partly, different at night than day. Dwarf mountainpine was the most preferred habitat in all seasons and was selected both for active behaviour (night) and resting (day) and hares avoided the most open habitats. Exploring the effects of season, time of day (day vs. night) and site, we found that habitat use by mountain hares did not differ between seasons or between the active (night) and resting (day) period of circadian cycle. Also, we found no effects of differences in landscape structure (habitat patchiness and heterogeneity) on the patterns of habitat selection. Hares always preferred the dense, forested habitats, which seemed to provide food resources as well as shelter from predators throughout the year.
\end{abstract}

(c) 2012 Deutsche Gesellschaft für Säugetierkunde. Published by Elsevier GmbH. All rights reserved.

\section{Introduction}

Animals make habitat choice as a result of balance between the costs and benefits perceived by the animal (Lima and Dill 1990; Lima and Bednekoff 1999). Habitat use is driven by habitat-related variation in factors such as forage quality and availability, shelter, presence of predators and mating system (e.g. Creel et al. 2005; Kuijper and Bakker 2008; Godvik et al. 2009). In fact, one of the most common trade-off faced by herbivores is when open habitats provide good forage and closed habitats provide shelter vs. predators (Godvik et al. 2009). The relative importance of finding food, mates and avoiding predators will change across different species of herbivores, but may also vary in space and time within populations of a single species (Rettie and Messier 2000).

Mammals have a 24-h activity rhythm, based on the endocrine melatonin rhythm of the pineal gland, synchronised with the environment by means of the light/dark cycle (Bartness and Goldman 1989). Since all activities carried out during the circadian cycle have fitness costs and benefits (Daan and Aschoff 1982),

\footnotetext{
* Corresponding author. Tel.: +39 0332 421538; fax: +39 0332421446

E-mail address: francesco.bisi@gmail.com (F. Bisi).
}

and if different habitats have differential survival costs/benefits for active behaviour than for resting/sleeping, an individual's space and habitat use is likely to differ between the active and the inactive part of the circadian cycle (e.g. Lima and Dill 1990; Hughes et al. 1994; Halle 2000). Hares do not have true nests, but use shelters under bushes, in fields, near rocks or even in snow (Angerbjörn and Flux 1995). Hence, hares might use some habitat types only for shelter and others only for foraging.

Habitat use of mountain hare (Lepus timidus) has been studied in Northern Europe (Hewson 1988, 1989; Hiltunen et al. 2004; Dahl 2005), but there is little information for Alpine populations (Genini-Gamboni et al. 2008). In Europe, the mountain hare is predominantly a species of mixed forest (Naumov 1947), although it reaches the highest densities in transition zone with open clearings (Lindlof et al. 1974) or in moorlands as in Scoltand (Watson and Hewson 1973). In landscapes in Scotland with a mosaic of open habitats suitable for feeding (e.g. pastures) and sheltered habitats (moorland) mountain hares tend to vary space and habitat use between day (resting) and night (foraging), using smaller night than day ranges (Flux 1970a,b; Hewson 1988). In contrast, in Ireland (Wolfe and Hayden 1996) and in Scotland (Rao et al. 2003), in less patchy landscapes with extensive areas of suitable foraging habitats day- and night ranges were similar and hares used the dominant habitat for both feeding and resting. 
In this study, we investigate habitat use of mountain hare in alpine ecosystem at three different time scales. Since the mountain hare is primarily nocturnal (Angerbjörn and Flux 1995), we expect that day home ranges include suitable resting (shelter) habitats, and night home ranges will primarily include suitable foraging habitats. Therefore, in a preliminary step we analysed activity patterns to determine when hares shifted from active to non-active behaviour. Next, we analysed habitat selection in two populations in areas with different habitat structure and composition, at different scales: First, we studied general habitat use on an annual basis. Second, since home-range size of mountain hare varies in relation to season (Bisi et al. 2011), we explored seasonal variation in habitat use. Third, we compared habitat use between day- and night ranges to explore whether habitats most preferred for shelter (day) were different from those preferred for feeding (night). Based on the studies carried out in Scotland, we predicted that day- and night habitat use will be similar in the study site dominated by a single extensive area of dwarf mountain pine, while different habitats will be used for resting (day) and foraging (night) in the 'patchy' study site.

\section{Material and methods}

Study sites

Mountain hares (Lepus timidus varronis) were studied in central Italian Alps in two different study sites. San Giacomo di Fraele (SG: elevation $1950-2500 \mathrm{~m}$ a.s.l., $46^{\circ} 32^{\prime} \mathrm{N}, 10^{\circ} 16^{\prime} \mathrm{E}$ ) in the Stelvio National Park is dominated by a homogeneous dwarf mountain pine (Pinus mugo) woodland with trees of both prostrate and arboreal habit (hereinafter called 'mountain pine site'). The undergrowth is composed of heather (Erica carnea), juniper (Juniperus communis), blueberry (Vaccinium myrtillus) and lingonberry (Vaccinium vitis-idaea). The second study site is in the nearby Vezzola (VZ) valley at $1700-2500 \mathrm{~m}$ a.s.l., approximately $6 \mathrm{~km}$ from SG. $\left(46^{\circ} 29^{\prime} \mathrm{N}, 10^{\circ} 16^{\prime} \mathrm{E}\right)$. The habitat is a mixture of forest patches of different size and composition (hereinafter called 'patchy site') with similar proportions of Norway spruce (Picea abies), Arolla pine (Pinus cembra) and larch (Larix decidua) and an homogeneous central patch of mountain pine (Pinus mugo). The undergrowth is composed mainly of heather (Erica carnea) and rhododendron (Rhododendron ferrugineum) with juniper (Juniperus communis) and blueberry (Vaccinium myrtillus). Composition of habitat types for both sites is shown in supplementary materials (Table S1). Landscape structure analysis (McGarigal and Marks 1994) showed that the patchy site has more fragmented habitat with more and smaller patches than the mountain pine site, indicating that the latter has a more homogeneous habitat structure. The mountain pine site also has a lower habitat diversity than the patchy site (supplementary materials, Table S1).

\section{Trapping and radio-tracking}

Between March 2005 and March 2008, we trapped 34 mountain hares using Tomahawk single door cat/rabbit collapsible traps $(66 \mathrm{~cm} \times 25 \mathrm{~cm} \times 25 \mathrm{~cm}$, model 205, Tomahawk Live Trap Co., Tomahawk, WI, USA) and long nets. During 2005 we tested traps in SG area and long nets in VZ (Nodari et al. 2005), as traps were more efficient in successive years we used only traps in both sites. In each study site, 25 traps were placed in a grid $(5 \times 5)$ spaced $70 \mathrm{~m}$ apart, for a total effort of 1383 trap-nights (2005, SG: 210; 2006, SG: 198, VZ: 248; 2007, SG: 203, VZ: 143; 2008, SG:207, VZ: 174). Traps were covered with a synthetic tissue and a smaller wire mesh $1 \mathrm{~cm} \times 1 \mathrm{~cm}$ to keep predators out. Traps were locked open and pre-baited for at least one week with dry "alfalfa" (trade name of a Medicago sativa based food preparation). The trapping period changed each year depending on snow cover, usually from the beginning of January to the end of March, the traps were set at dusk and checked at dawn (Nodari et al. 2005). We trapped and radio-tagged 21 adult hares ( 10 males and 11 females), and 13 subadults ( 6 males and 7 females). We radio-collared the hares with ATS adjustable necklace transmitters weighing $35 \mathrm{~g}$ with a $24 \mathrm{~h}$ set mortality sensor (M1930 transmitters, Advanced Telemetry Systems Inc., Isanti, MN, USA). Hares were sexed and aged (subadult, under 7-8 months old, or adult) by observation of external genitals and by Stroh's tubercle palpation (Stroh 1931). Radio tagged hares were located thorough triangulation techniques.

Radio-tracking was carried out as in Bisi et al. (2011). At each fix, a hare's location and activity (active, not active) were recorded. Activity was determined based on the variation in signal intensity over a 1-min period: when hares were resting (motionless) intensity remained stable, while the signal of active hares (moving or changing body position) was characterised by marked variation in intensity. Signal intensity was observed both acoustically and visually using the signal strength indicator (DC milliamperes indicator).

\section{Activity patterns}

To analyse activity patterns, we calculated the proportion of active fixes $5 \mathrm{~h}$ before and $5 \mathrm{~h}$ after sunrise and sunset. Arcsin of the square root of proportion active fixes per hour was used as dependent variable in two Linear Mixed Models (LMM) one explored changes in activity with respect to sunrise, the second with respect to sunset. Hour with respect to sunrise (from -5 to +5 ) or to sunset (from -5 to +5 ), season and their interaction were included as fixed effects. Since data of a single individual were used in different periods (seasons), we used individual as a repeated measure to account for pseudo-replication, analysis were performed using $\mathrm{R}$ package lme4 (Bates et al. 2011). The distribution of the residuals was explored using the Shapiro-Wilk statistic and did not deviate from normality. Interpretation of pairwise differences was based on Differences of Least Squares Means.

\section{Home range analysis}

For each year, we estimated seasonal home range size: winter (December-March, ground continuously covered with snow), spring-summer (April-August, defined "breeding season", this is the season with vegetation growth, mating and breeding activity), and autumn (September-November, post-breeding season, with no vegetation growth and no continuous snow cover, from Bisi et al. 2011). In the next step we separated locations taken during the day (day-ranges) from those taken at night (night-ranges), within each season and year, and estimated size of day- and night home ranges separately (between 20 and 599 fixes used per range estimate). Dividing an animal's day- from night-range was based on the exact hour of sunrise and sunset per day at the latitude of our study sites (day fixes between sunrise and sunset, night fixes between sunset and next sunrise).

Home range size was estimated with the 95\% fixed Kernel Density Estimator as explained in Bisi et al. (2011) using R package Adehabitat (Calenge 2006). Individual variation in home range size was investigated using GLMM with individual added as a repeated measure to account for pseudo-replication. We started from a saturated model with dependent variable Ln-transformed KDE95\%, and number of fixes, day-night, season, age, sex, study site and their interactions as fixed effects. Data on home range size met assumptions of homogeneity of variances after Ln-transformation. The distribution of the residuals was explored at each model step using the Shapiro-Wilk statistic and did not deviate from normality. Using a stepwise backward procedure we identified the final 
model containing only significant effects $(p<0.05)$. Interpretations of final model were based on Tukey's HSD test (Honestly Significant Difference, hereinafter indicated as HSDt).

Sample sizes (number of home range estimates) for each factor, or combination of factors, used in the above GLMM was: total $n=168$; day $n=70$, night $n=98$; autumn $n=43$ (21 males, 22 females), winter $n=44$ ( 21 males, 23 females), spring-summer $n=81$ (39 males, 42 females); adult $n=125$, subadults $n=43$; male $n=81$, female $n=87$.

Distribution of residual values of the selected model did not deviate from a normal distribution (Shapiro-Wilk, $p>0.10$ ). Home range overlap, between an individual's day- and night-range within each season, was expressed as mean percentage of overlap using the formula: $O_{1,2} /\left(A_{1}+A_{2}-O_{1,2}\right)$, where $O_{1,2}=$ the common area between the two home ranges, $A_{1}=$ the total area of the day-range and $A_{2}=$ the total area of the night-range (Dahl 2005).

\section{Habitat selection}

Habitat availability in each study site was determined by the proportion of each habitat type within the 100\% MCP of all fixes from all individuals (SG 1475 ha, VZ 1069 ha, Table 1). Hence proportion habitat available was the same for all hares in each of the sites. We first tested whether habitat use differed from random, using compositional analysis which examines habitat use in proportion to availability (Aebischer et al. 1993).

Compositional analysis takes the log-ratio differences of used and available habitat proportions to determine habitat-use preferences for each individual. An individual's use of habitat ${ }_{i}$ was determined as the proportion of habitat $t_{i}$ inside the $95 \% \mathrm{KDE}$, calculated using all fixes over the entire period the individual was monitored. In a second step, we calculated the proportion of each habitat, for the day- and the night-range separately, to estimate an individual's day- (resting) and night-time (active) habitat use, in each season (Manly et al. 1993; Rettie and Messier 2000). We calculated the selection ratio for each habitat i as $w_{i}=$ (proportion habitat $_{\mathrm{i}}$ used/proportion habitat ${ }_{\mathrm{i}}$ available), and then standardised following the equation $b_{\mathrm{i}}=w_{\mathrm{i}} / \Sigma\left(w_{\mathrm{i}}\right)$ (Manly et al. 1993).

We used the habitat-specific indices $\left(b_{i}\right)$ for each animal's range in SG ( $b_{\mathrm{i}}$ for 4 habitat types) and in VZ ( $b_{\mathrm{i}}$ for 8 habitat types) as dependent variable in a Multiple Analysis of Variance (MANOVA), testing the effect of sex, season and day-night index. All analyses we performed using R software 2.9.0 (R Development Core Team 2009).

\section{Results}

\section{Activity patterns}

The percentage active fixes differed between seasons at sunset (SS) and at sunrise (SR), (SS: LMM, season effect $F_{2,730}=32.3$; $p<0.01$; SR: LMM, season effect $\left.F_{2,616}=22.3 ; p<0.01\right)$ and according to hour (SS: $F_{10,730}=63.2 ; p<0.01 ;$ SR: $F_{10,616}=39.6 ; p<0.01$ ). There was no significant season by hour interaction (SS: season $\times$ hour $F_{20,730}=1.55 ; p=0.06 ;$ SR: $F_{20,616}=1.47 ; p=0.09$ ). Overall, percentage activity of mountain hares was lower in winter than in the other seasons for sunset (DLSM, all $p<0.001$ ), but similar in autumn and breeding season (DLSM, $p=0.63$ ). Also of sunrise in winter there is a lower percentage of activity and autumn had the higher percentage of activity (DLSM, all $p<0.01$ ).

Within the circadian cycle there was a significative decrease in activity $1 \mathrm{~h}$ after sunrise (DLSM 0-1: $p<0.001$ ) and there was a significative increase of activity between sunset and the first hour after sunset and between the first and the second hour after sunset (DLSM: $0-1: p<0.01 ; 1-2: p=0.02$ ) (Fig. 1). DLSM of the other consecutive hours were not significative $(p>0.05)$.

\section{Day-night home ranges}

Individual variation in home range size was large (mean $\pm \mathrm{SD}=48.6 \pm 35.1 \mathrm{ha}$ ). Mountain hares used larger night than day ranges (day-night $F_{1,160}=5.63 ; p=0.018$, Fig. 2). Moreover, home range size differed between age-classes, seasons, and there was a significant sex by season interaction (season $F_{2,160}=7.61$; $p<0.01$; age $F_{1,160}=6.27 ; p=0.013$; sex by season $F_{3,160}=3.25$; $p=0.023$ ). Subadults used larger day and night home ranges than adults, and in winter and breeding season day-night ranges were larger than in autumn (HSDt winter $>$ autumn, $p=0.019$ and breeding season $>$ autumn, $p<0.01)$. Female in autumn used smaller ranges than males in the same season (HSDt, $p=0.037$ ), possibly related to poorer body condition after breeding and moult.

Average ( \pm SD) overlap between day and night range of single hares was $36 \pm 11 \%$ (range $5-60 \%$ ). There was no difference between sites, sexes, seasons or age-classes (GLMM, all $p>0.20$ ). Hence, on average, the overlap of a hare's day and night range did not differ between the mountain pine and the patchy site.

\section{Habitat selection}

The two study sites differed in habitat types and their proportion availability (Table 1 ). In both sites, hares strongly selected certain habitat types and avoided others (mountain pine site: Wilks' lambda $=0.0879$; $\mathrm{df}=3 ; p<0.01$; patchy site: Wilks' lambda $=0.0074 ; \mathrm{df}=7 ; p<0.01)$. Hares strongly selected dwarf mountain pine, and also alpine grassland, at SG, but strongly avoided alpine grassland at the patchy site where a higher diversity of habitat types was available (Table 1 and supplementary materials Table S2).

In the mountain pine site, alpine grassland was used less in autumn than in other seasons (Table 2, season effect $F_{2,69}=5.07 ; p=0.009$; HSDt winter $>$ autumn $p<0.01$; breeding season $>$ autumn $p<0.01$ ). There was no effect of season on habitat use indices for the other habitat types in any season (Table 2, no season effect in MANOVA). Finally, there was no effect of day vs. night ranges on proportion habitat use in either site (Table 2, day-night effect and day-night by season interactions, all $p>0.05$ ). This means that hares selected and avoided the same habitat types during resting (day) than for foraging (night) in both study sites.

\section{Discussion}

Mountain hares in the Alps were active at night, with a marked increase in activity the first $2 \mathrm{~h}$ after sunset and a strong decrease the first hour after sunrise. This pattern was constant in all seasons. Hence, we felt confident to consider night home ranges as foraging ranges and day home ranges as areas including the resting and hiding sites of mountain hares. Day- and night ranges of individuals overlapped, on average, for one third of their size, independent of the animal's sex or age. Although night home ranges were larger than day home ranges, hares selected (or avoided) the same habitat types for foraging at night and for resting during the day. These patterns were consistent in both study sites; hence habitat composition and patchiness did not affect space use and habitat selection of alpine mountain hares.

Environmental factors that can affect hare behaviour vary considerably over time. In the Alps, one of the most substantial changes in the environment is seasonal variation in resource availability, linked to the plant growing season and the amount of snow cover. However, on a shorter time-scale, the environment also changes 
Table 1

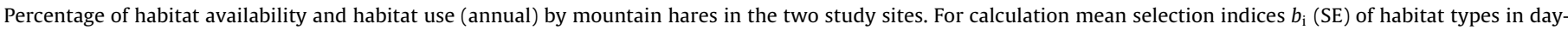
and night ranges see methods.

\begin{tabular}{|c|c|c|c|c|}
\hline Habitat category & Available & Used & $b_{\mathrm{i}}$ day & $b_{\mathrm{i}}$ night \\
\hline \multicolumn{5}{|l|}{ (a) Mountain pine site } \\
\hline Landslides & 11.44 & 5.34 & $0.100(0.014)$ & $0.129(0.016)$ \\
\hline Alpine grassland & 9.85 & 6.01 & $0.185(0.016)$ & $0.163(0.012)$ \\
\hline Dwarf-mountain pine & 41.58 & 76.26 & $0.632(0.022)$ & $0.599(0.021)$ \\
\hline Rocks & 37.13 & 12.38 & $0.084(0.008)$ & $0.102(0.009)$ \\
\hline \multicolumn{5}{|l|}{ (b) Patchy site } \\
\hline Landslides & 7.43 & 6.39 & $0.024(0.012)$ & $0.030(0.008)$ \\
\hline Alpine grassland & 13.56 & 3.35 & $0.016(0.007)$ & $0.009(0.003)$ \\
\hline Dwarf-mountain pine & 0.42 & 4.07 & $0.431(0.057)$ & $0.454(0.045)$ \\
\hline Rocks & 16.64 & 4.78 & $0.019(0.005)$ & $0.021(0.004)$ \\
\hline Pastures & 26.44 & 36.19 & $0.091(0.019)$ & $0.103(0.023)$ \\
\hline Coniferous & 20.03 & 13.62 & $0.042(0.010)$ & $0.049(0.008)$ \\
\hline Dry meadows & 8.96 & 4.11 & $0.049(0.013)$ & $0.039(0.010)$ \\
\hline Swiss stone pine dominated forest (SSP) & 6.52 & 27.46 & $0.321(0.034)$ & $0.300(0.028)$ \\
\hline
\end{tabular}
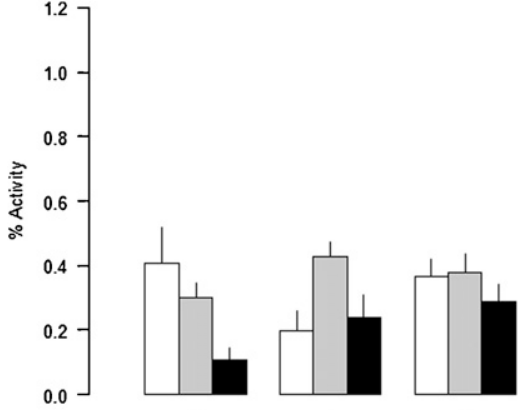

4

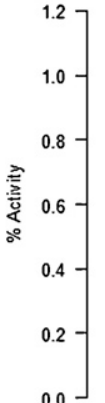

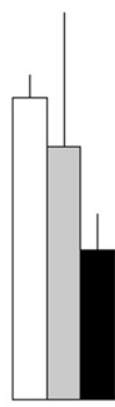

$-5$

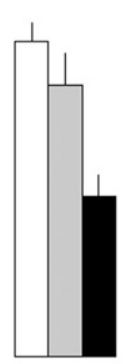

$-4$

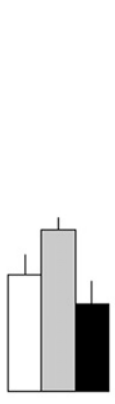

$-2$

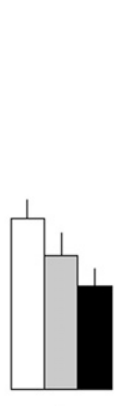

$-1$

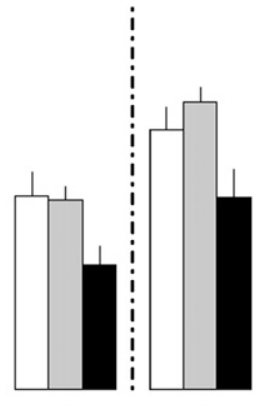

0

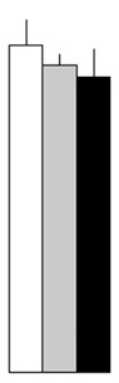

2

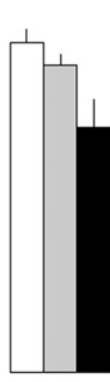

3

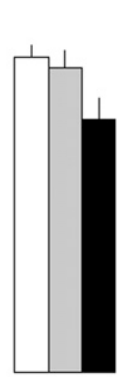

4
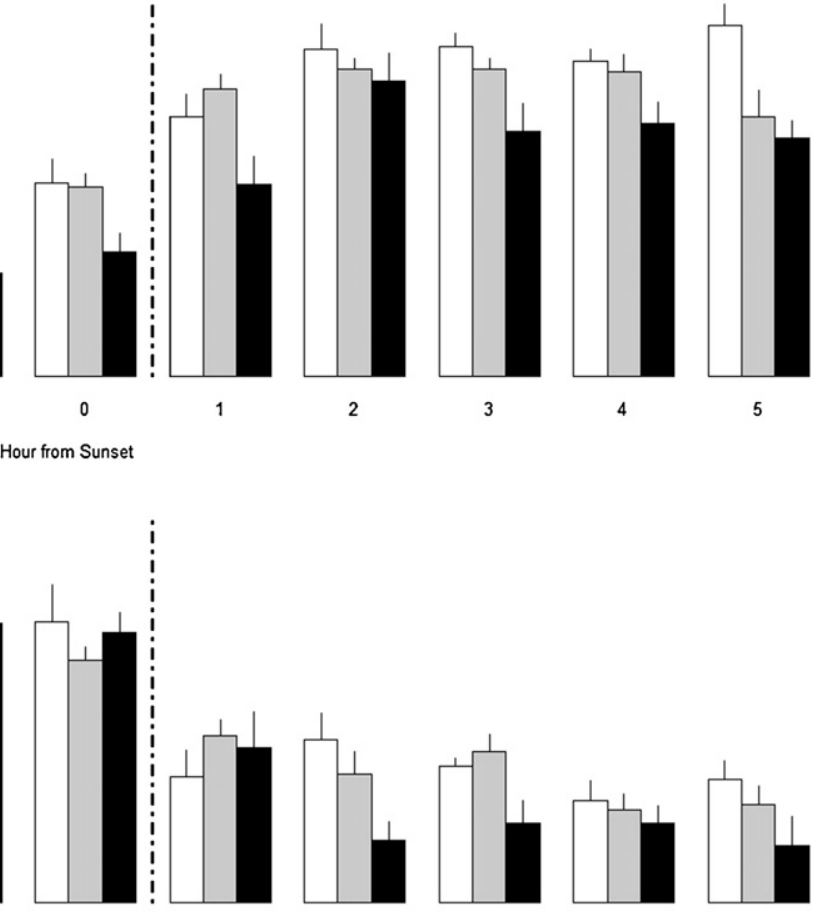

0

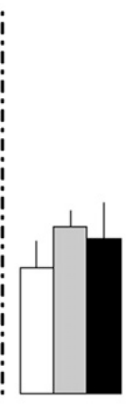

1

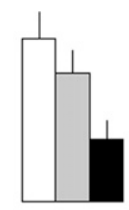

2

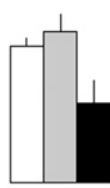

3

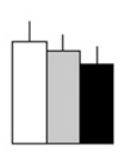

4

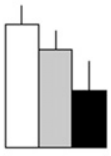

5

Hour from sunrise

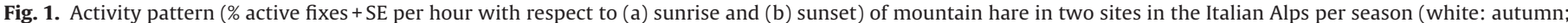
grey: breeding season; black: winter). Dashed lines indicate time of sunrise and sunset.

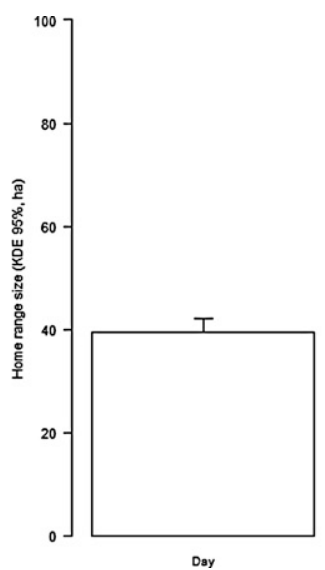

Day

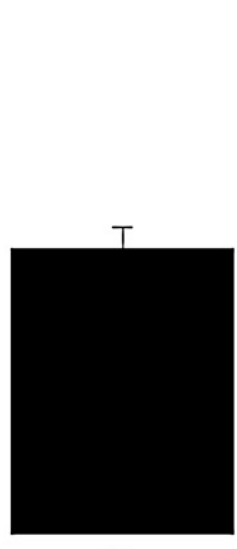

Night

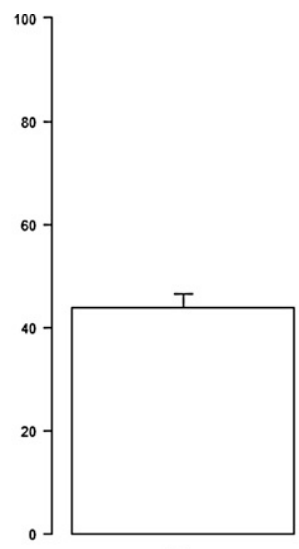

Adults

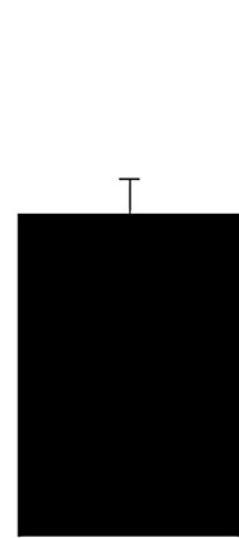

Subadults

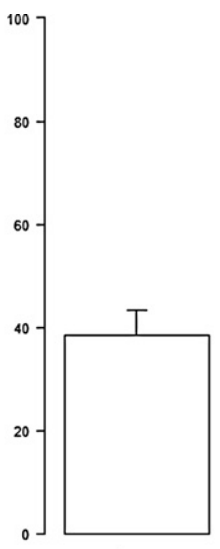

Autumn

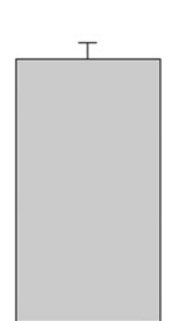

Breeding

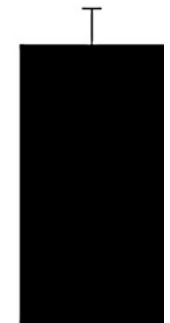

Winter

Fig. 2. Average (+SE) home range size (ha) of mountain hares in the Italian Alps; effects of: (a) day- vs. night home range, (b) age and (c) season. 
Table 2

MANOVA of the two study sites, habitat categories as dependent variables.

\begin{tabular}{|c|c|c|c|c|c|c|}
\hline \multirow[t]{2}{*}{ Dependent variable } & \multicolumn{2}{|l|}{ Season effect } & \multicolumn{2}{|c|}{ Day-night effect } & \multicolumn{2}{|c|}{ Day-night $\times$ season } \\
\hline & $F(\mathrm{df}=2,69)$ & $p$ & $F(\mathrm{df}=1,91)$ & $p$ & $F(\mathrm{df}=2,91)$ & $p$ \\
\hline \multicolumn{7}{|l|}{ (a) Mountain pine site } \\
\hline Landslides & 0.91 & 0.42 & 1.75 & 0.19 & 0.37 & 0.69 \\
\hline Alpine grassland & 5.07 & $0.009^{*}$ & 1.46 & 0.23 & 0.81 & 0.45 \\
\hline Dwarf mountain pine & 1.48 & 0.23 & 1.10 & 0.30 & 0.17 & 0.85 \\
\hline Rocks & 0.75 & 0.47 & 3.93 & 0.05 & 1.98 & 0.14 \\
\hline \multirow[t]{2}{*}{ Dependent variable } & \multicolumn{2}{|l|}{ Season effect } & \multicolumn{2}{|c|}{ Day-night effect } & \multicolumn{2}{|c|}{ Day-night $\times$ season } \\
\hline & $F(\mathrm{df}=2,44)$ & $p$ & $F(\mathrm{df}=1,65)$ & $p$ & $F(\mathrm{df}=2,65)$ & $p$ \\
\hline \multicolumn{7}{|l|}{ (b) Patchy site } \\
\hline Dry meadows & 0.09 & 0.92 & 0.41 & 0.52 & 0.83 & 0.44 \\
\hline Pastures & 1.81 & 0.18 & 0.12 & 0.72 & 1.21 & 0.30 \\
\hline Landslides & 2.09 & 0.14 & 0.00 & 0.98 & 0.02 & 0.98 \\
\hline Alpine grassland & 1.98 & 0.15 & 1.02 & 0.32 & 0.96 & 0.39 \\
\hline Conifers & 0.45 & 0.64 & 0.25 & 0.62 & 0.27 & 0.76 \\
\hline Dwarf mountain pine & 0.91 & 0.41 & 0.10 & 0.75 & 0.02 & 0.98 \\
\hline Swiss stone pine dom. & 1.08 & 0.35 & 0.33 & 0.56 & 0.33 & 0.72 \\
\hline Rocks & 0.45 & 0.64 & 0.17 & 0.68 & 1.34 & 0.27 \\
\hline
\end{tabular}

* Significant factor.

predictably in the course of the 24-h day, where factors such as predation risk often vary strongly with the dark-light cycle (Halle 2000).

In the Alps, mountain hares were more active at night than during day-light, confirming the typical nocturnal activity pattern documented in other parts of the species' range (Angerbjörn and Flux 1995). Activity patterns changed between seasons in parallel with changes in the timing of the light-dark cycle. The results suggest that during the day, mountain hares should select habitats where they remain concealed from day-active predators, which, in our sites, are golden eagle (Aquila chrysaetos), goshawk (Accipiter gentilis) which may prey on juvenile hares, and red fox (Vulpes vulpes). However, golden eagle was observed hunting only in open habitats such as alpine grassland and rocks, while red fox, the major predator of hares in our sites (about 20\% of monitored hares were predated by fox, our unpubl. data) is mainly active around sunrise and dusk, and probably at night (based on fresh tracks in snow found during many trap controls carried out immediately after sunrise).

High levels of active behaviour during night hours corresponded with the use of larger ranges. At night, hares made more exploratory and/or foraging movements probably related to finding (seasonal) food sources. On average, an individual's night and day home range overlapped 33\%, suggesting that selective pressures affecting space use were, at least partly, different at night than during the day. However, these partial shifts between day- and night ranges did not correspond with changes in habitat selection.

Differential day vs. night space use was also found in some Scottish mountain hare populations, but with a pattern that was the opposite from that in the Alps. In heterogeneous habitats in Scotland, characterised by distinct patches of grassland, heather moorland and forest, hares used smaller night than day ranges, feeding mainly in small pastures surrounded by heather moorland which offered good shelter for resting during day-light hours (Flux 1970b; Hewson 1988). In contrast, in less patchy habitats in Scotland there were no significant differences between day- and night home ranges, but the trend (night larger than day ranges) was similar as in our study (Wolfe and Hayden 1996; Rao et al. 2003). Finally, separating day from night ranges, we found smaller ranges in autumn, a season that could be a critical period of the year for hares in relation with the onset of winter moult and the physiological changes related to shifts in the diet (Pulliainen and Tunkkari 1987; Angerbjörn and Flux 1995).
We were unable to explore the importance of predation pressure on the observed patterns of space- and habitat use. Other studies showed that red foxes are important predators of different hare species, but predation pressure varies in relation to geographic region and landscape or habitat structure (e.g. Panek 2009; Carlsson et al. 2010). The importance of predator pressure on mountain hare densities, and behaviour are likely to vary in relation to densities of both prey and predator and with habitat structure (see also Hik 1995; Newey et al. 2007). The short time-span of our study did not allow us to explore a possible relationship between variation in fox density and hare space and/or habitat use.

Earlier studies in Scotland and Scandinavia showed that landscape structure, in particular patchiness and heterogeneity, affected differences in habitat selection for foraging and resting (Litvaitis et al. 1985; Hewson 1988; Wolfe and Hayden 1996; Rao et al. 2003). Hence, we expected differences in day (resting) and night (foraging) habitat use between our study sites.

The use of preferred habitats did not differ between night and day or between our study sites. Thus, in this study in the Italian Alps, differences between sites in landscape patchiness and heterogeneity did not affect habitat selection by mountain hares, in contrast with our prediction. We found that dwarf mountain-pine was the most preferred habitat type in all seasons and was selected both for active behaviour (night) and for resting (day). Although hare density differed between the two study sites (SG 12 and VZ 4 hares $/ \mathrm{km}^{2}$ ), there was no site effect either on home range size (Bisi et al. 2011) or overall pattern of habitat selection: hence in our study density did not appear to be a factor affecting habitat selection.

Dwarf mountain-pine was characterised by providing food and shelter, low branches often reaching to the ground, throughout the year. Our measures of plant biomass production of Carex sempervirens, Erica carnea, Vaccinium vitis-idae, Melampyrum sylvaticum, Sesleria varia, Briza media, and Juniperus nana in this habitat (unpubl. data) suggested that it provided a good food supply in the breeding season and in autumn. We further observed that during winter, mountain-pine buds, leaves and bark were the only food source available to mountain hares which, in our sites, did not dug through snow searching for shrubs. Leaves and buds from other conifers only occurred several metres above ground and thus could not be reached by hares when the ground was covered with snow.

In other studies it has been argued that strong selection for dense woodland or woodland with a well-developed canopy was 
mainly due to these habitats providing shelter and concealment from predators (Litvaitis et al. 1985; Angerbjörn and Flux 1995). Differently, in extensive moorland with plantings of Scots pine Pinus sylvestris and downy birch Betula pubescens in Scotland, mountain hare always preferred patches with heather over woodland habitat (Rao et al. 2003). This might be related with dense heather offering better food (and shelter) than the pine-birch wood patches. Studies in southern Finland (Hiltunen et al. 2004; Hiltunen and Kauhala 2006) suggested that mountain hares selected areas with a dense shrub-layer because they offer both food and shelter against predators, characteristics of habitat quality that in our study were supplied by the dwarf-mountain pine woodland.

There was little seasonal variation in habitat use. Only in the mountain pine site, open habitat, the alpine grassland, was more strongly avoided in autumn, when hares are in the middle of the moult (Flux 1970a), than in the other seasons. Over all seasons and in both sites, closed (forested) habitats were preferred over open habitats with less shelter (grassland, dry meadows, rocks).

We conclude that habitat use by Alpine mountain hares did not differ between seasons or between the active (night) and resting (day) period of circadian cycle. Also, we found no effects of differences in landscape structure (habitat patchiness and heterogeneity) on the patterns of habitat selection. Hares always preferred the dense, forested habitats, which seemed to provide food resources as well as shelter from predators throughout the year.

\section{Acknowledgements}

Thanks to the Sondrio Province personnel: Andrea Vanotti, Maria Ferloni and all the game wardens; the Stelvio National Park personnel: Luca Pedrotti, Alessandro Gugiatti and all the park rangers. Alessandro Bianchi for the veterinary support. Comments by two anonymous referees and the subject editor (Prof. Dr. Heiko Rödel) greatly helped to improve the ms. The study was part of the MoHaRe (Mountain Hare Research) project, carried out by University of Insubria, Varese and Istituto Oikos NGO, Milan. Financial support was provided by the Wildlife Service of the Province of Sondrio and the Stelvio National Park. This paper is dedicated to the memory of our wonderful and charismatic colleague, Guido Tosi, who recently passed away.

\section{Appendix A. Supplementary data}

Supplementary data associated with this article can be found, in the online version, at http://dx.doi.org/10.1016/j. mambio.2012.05.004.

\section{References}

Aebischer, N.J., Robertson, P.A., Kenward, R.E., 1993. Compositional analysis of habitat use from animal radio-tracking data. Ecology 74, 1313-1325.

Angerbjörn, A., Flux, J.E.C., 1995. Lepus timidus. Mammal. Spec. 495, 1-11.

Bartness, T.J., Goldman, B.D., 1989. Mammalian pineal melatonin: a clock for all seasons. Experientia 45, 939-945.

Bates, D., Maechler, M., Bolker, B., 2011. Ime4: linear mixed-effects models using S4 classes. R package version 0.999375-42.

Bisi, F., Nodari, M., Dos Santos Oliveira, N.M., Masseroni, E., Preatoni, D.G., Wauters, L.A., Tosi, G., Martinoli, A., 2011. Space use patterns of mountain hare (Lepus timidus) on the Alps. Eur. J. Wildl. Res. 57, 305-312.

Calenge, C., 2006. The package adehabitat for the R software: a tool for the analysis of space and habitat use by animals. Ecol. Model. 197, 516-519.

Carlsson, N.O.L., Jeschke, J.M., Holmqvist, N., Kin, J., 2010. Long-term data on invaders: when the fox is away, the mink will play. Biol. Invasions 12, 633-641.
Creel, S., Winnie Jr., J., Maxwell, B., Hamlin, K., Creel, M., 2005. Elk alter habitat selection as an antipredator response to wolves. Ecology 86, 3387-3397.

Daan, S., Aschoff, J., 1982. Circadian contributions to survival. In: Aschoff, J., Daan, S., Groos, G.A. (Eds.), Vertebrate Circadian Systems. Springer, Berlin/Heidelberg/New York, pp. 305-321.

Dahl, F., 2005. Distinct seasonal habitat selection by annually sedentary mountain hares (Lepus timidus) in the boreal forest of Sweden. Eur. J. Wildl. Res. 51, 163-169.

Flux, J.E.C., 1970a. Life history of the mountain hare (Lepus timidus scoticus) in northeast Scotland. J. Zool. Lond. 161, 75-123.

Flux, J.E.C., 1970b. Colour change of mountain hares (Lepus timidus scoticus) in northeast Scotland. J. Zool. Lond. 162, 345-358.

Genini-Gamboni, A.S., Bisi, F., Masseroni, E., Nodari, M., Preatoni, D., Wauters, L., Martinoli, A., Tosi, G., 2008. Home range dynamics of mountain hare (Lepus timidus) in the Swiss Alps. Hystrix It. J. Mammal. 19 (2), 157-163.

Godvik, I., Loe, L., Veiberg, V., Langvatn, R., Mysterud, A., 2009. Scale, trade-offs, and functional responses in red deer habitat selection. Ecology 90, 699-710.

Halle, S., 2000. Ecological relevance of daily activity patterns. In: Halle, S., Stenseth, N.C. (Eds.), Activity Patterns in Small Mammals: An Ecological Approach. Springer, Berlin Heidelberg New York, pp. 67-90, Ecological studies 141.

Hewson, R., 1988. Spacing and habitat preference of mountain hares in Shetland. J. Appl. Ecol. 25, 397-407.

Hewson, R., 1989. Grazing preferences of mountain hares on heather moorland and hill pastures. J. Appl. Ecol. 26, 1-11.

Hik, D.S., 1995. Does risk of predation influence population dynamics? Evidence from the cyclic decline of snowshoe hares. Wildl. Res. 22, 115-129.

Hiltunen, M., Kauhala, K., Linden, H., 2004. Habitat use of the mountain hare Lepus timidus in summer: the importance of different vegetation layers. Acta Theriol. 49, 479-490.

Hiltunen, M., Kauhala, K., 2006. Selection of sapling stand habitats by the mountain hare (Lepus timidus) during winter. Mamm. Biol. 71, 183-189.

Hughes, J.J., Ward, D., Perrin, M.R., 1994. Predation risk and competition affect habitat selection and activity of Namib Desert gerbils. Ecology 75, 1397-1405.

Kuijper, D.P.J., Bakker, J.P., 2008. Unpreferred plants affect patch choice and spatial distribution of Brown hares. Acta Oecol. 34, 339-344.

Lima, S.L., Bednekoff, P.A., 1999. Temporal variation in danger drives antipredator behaviour: the predation risk allocation hypothesis. Am. Nat. 153, 649-659.

Lima, S., Dill, L., 1990. Behavioural decisions made under the risk of predation: a review and prospectus. Can. J. Zool. 68, 619-649.

Lindlof, B., Lindostrom, E., Pehrson, A., 1974. On activity, habitat selection and diet of the mountain hare (Lepus timidus L.) in winter. Viltrevy 9, 27-43.

Litvaitis, J.A., Sherburne, J., Bissonette, J., 1985. Influence of understory characteristics on snowshoe hare habitat use and density. J. Wildl. Manage. 49, 866-873.

Manly, B.F., McDonald, L.L., Thomas, D., 1993. Resource selection by animals. In: Statistical Design and Analysis for Field Studies. Chapman and Hall, London.

McGarigal, F., Marks, B.J., 1994. FRAGSTATS. Spatial Pattern Analysis Program for Quantifying Landscape Structure. Forest Science Department, Oregon State University, Covallis, OR

Naumov, S.P., 1947. Ecology of the Snow hare Lepus timidus L.: Theoretical Foundations for the Prognosis of the Species' Population. Moscow Society of Naturalists, Moscow.

Newey, S., Dahl, F., Willebrand, T., Thirgood, S., 2007. Unstable dynamics and population limitation in mountain hares. Biol. Rev. 82, 527-549.

Nodari, M., Masseroni, E., Preatoni, G., Wauters, L.A., Tosi, G., Martinoli, A., 2005. Livetrapping success of the mountain hare (Lepus timidus) in the southern Italian Alps. Hystrix It. J. Mammal. 16 (2), 143-148.

Panek, M., 2009. Factors affecting predation of red foxes Vulpes vulpes on brown hares Lepus europaeus during the breeding season in Poland. Wildl. Biol. 15, 345-349.

Pulliainen, E., Tunkkari, P.S., 1987. Winter diet, habitat selection and fluctuation of a mountain hare Lepus timidus population in Finnish Forest Lapland. Ecography 10, 261-267.

Rao, S.J., Iason, G.R., Hulbert, I.A.R., Racey, P.A., 2003. The effect of establishing native woodland on habitat selection and ranging of moorland hares (Lepus timidus), a flexible forager. J. Zool. Lond. 260, 1-9.

R Development Core Team, 2009. R: A Language and Environment for Statistical Computing. R Foundation for Statistical Computing, Vienna, Austria.

Rettie, W., Messier, F., 2000. Hierarchical habitat selection by woodland caribou: its relationship to limiting factors. Ecography 23, 466-478.

Stroh, G., 1931. Zwei sichere Altersmerkmale beim Hasen. Berl. Tierärztl. Wochenschr. 12, 180-181.

Watson, A., Hewson, R., 1973. Population densities of mountain hares (Lepus timidus) on western Scottish and Irish moors and on Scottish hills. J. Zool. Lond. 170, 151-159.

Wolfe, A., Hayden, T.J., 1996. Home range sizes of Irish mountain hares on coastal grassland. Biol. Environ. Proc. R. Ir. Acad. 96B, 141-146. 